\title{
cDNA Cloning, Genomic Structure, and Chromosome Mapping of the Human Epithelial Membrane Protein CL-20 Gene (EMP1), a Member of the PMP22 Family
}

\author{
Yan Chen, ${ }^{1,2}$ Alex Medvedev, ${ }^{2}$ Peter Ruzanov, Keith W. Marvin, ${ }^{3}$ and Anton M. Jetten ${ }^{4}$ \\ Cell Biology Section, Laboratory of Pulmonary Pathobiology, National Institute of Environmental Health Sciences, National \\ Institutes of Health, Research Triangle Park, North Carolina 27709
}

Received April 26, 1996; accepted November 20, 1996

\begin{abstract}
CL-20 is a novel gene encoding a protein that is structurally related to but distinct from the peripheral myelin protein PMP22. Like PMP22, CL-20 is likely to play important roles in the regulation of cell proliferation, differentiation, and cell death. In this study, we describe the cloning and sequencing of a cDNA encoding the human homologue of CL-20 and characterize the genomic structure of this gene. The hCL-20 gene (HGMW-approved symbol EMP1) encodes a protein of 157 amino acids that exhibits $76 \%$ identity to the rabbit CL-20 and to the rat EMP-1, which have been described recently, and $39 \%$ identity to human PMP22. CL-20 contains four hydrophobic domains, suggesting that it is an integral membrane protein. In particular the second hydrophobic domain encoded within the fourth exon is highly conserved among CL-20, EMP-1, and PMP22, suggesting a functional role for this region. CL-20 mRNA is abundant in squamous-differentiated bronchial epithelial cells; however, low levels of CL-20 mRNA can be detected in several human tissues by Northern analysis. Retinoic acid, which inhibits squamous differentiation, represses CL-20 expression in normal human bronchial epithelial cells. The genomic structure of the $h C L-20$ gene was analyzed using a P1 vector containing this gene. The hCL20 gene contains five exons about $0.2,0.12,0.1,0.14$, and $2.2 \mathrm{~kb}$ and four introns about 15, 1.9, 0.1 , and $0.7 \mathrm{~kb}$. We have mapped the hCL-20 gene to chromosome 12p12 by fluorescence in situ hybridization. 1997 Academic Press
\end{abstract}

\section{INTRODUCTION}

Squamous differentiation is a multistep process that can be observed in epithelial cells of many different

\footnotetext{
Sequence data from this article have been deposited with the GenBank/EMBL Data Libraries under Accession No. U77085.

${ }^{1}$ Present address: Blood Research Institute, Blood Center of Southeastern Wisconsin, P.O. Box 2178, Milwaukee, WI 53233.

2 The first two authors contributed equally to the paper.

${ }^{3}$ Present address: Department of Pharmacology \& Clinical Pharmacology, University of Auckland, Auckland, New Zealand.

${ }^{4}$ To whom correspondence should be addressed. Telephone: (919) 541-2768. Fax: (919) 541-4133. E-mail: jetten@iehs.nih.gov.
}

tissues. Early in this terminal pathway of differentiation, cells undergo irreversible growth arrest that is accompanied by a down-regulation of several cell cycle control genes, including RB and cdc2 (J etten et al., 1992; Saunders and J etten, 1994). This is followed by the induction of differentiation-specific genes such as expression of several keratins and proteins involved in the formation of the cross-linked envelope such as transglutaminase type I and cornifins (Eckert and Rorke, 1989; J etten et al., 1992; Marvin et al., 1992). Recently, we cloned a cDNA CL-20 encoding a novel protein from a cDNA library prepared from squamousdifferentiated rabbit tracheal epithelial cells (Marvin et al., 1995). This gene is expressed at low levels in undifferentiated tracheobronchial cells and becomes highly expressed when these cells undergo squamous differentiation. The rabbit CL-20 protein exhibits a $75 \%$ identity with the recently reported epithelial membrane protein, EMP-1 (Taylor et al., 1995), which might be the rat homologue of CL-20. The rabbit CL20 exhibits moderate (43\%) homology to the human peripheral myelin protein, PMP22 protein (also known as gas3) (Manfioletti et al., 1990; Welcher et al., 1991; Snipes et al., 1992; Suter et al., 1992). CL-20, EMP-1, and PMP22 exhibit a great structural similarity, suggesting that they belong to the same gene subfamily. Point mutations in the mouse PMP22 gene are responsible for the severe myelin deficiencies and excessive proliferation of Schwann cells that underliethe neuropathies in trembler and trembler-J mice (Suter et al., 1992). Genetic alterations in the PMP22 gene havealso been implicated in several neurological disorders in humans, such as Charcot-Marie-Tooth disease and Dejerine- Sottas syndrome (Valentijn et al., 1992; Matsunami et al., 1992; Timmerman et al., 1992; Patel et al., 1992; Roa et al., 1993; Patel and Lupski, 1994). Furthermore, genetic alterations in the PMP22 gene have been linked to hereditary neuropathy with liability to pressure palsies (Chance et al., 1994; Nicholson et al., 1994). Transgenic rats that overexpress PMP22 
exhibit abnormalities closely resembling those observed in patients with Charcot-Marie-Tooth disease (Sereda et al., 1996). PMP22 is up-regulated during growth arrest of mouse NIH 3T3 fibroblasts and has a pronounced effect on the length of the G1 phase of the cell cycle in cultured Schwann cells (Ciccarelli et al., 1990; Zoidl et al., 1995). Recently, it has been demonstrated that overexpression of PMP22 in NIH 3T3 cells results in apoptosis (Fabbretti et al., 1995). These observations suggest that PMP22 plays an important structural role in maintaining myelin compaction in peripheral nerves and has additional functions, including regulation of cell proliferation and differentiation, in some nonneural cell types.

In this study, we have cloned and sequenced a cDNA encoding the human homologue of the epithelial membrane protein CL-20 $20^{5}$ and compared its amino acid sequence and structure to those of the rabbit homologue and to those of rat EMP-1 and human PMP22. We have examined its expression pattern in several human tissues and demonstrated that CL-20 is highly induced when normal human bronchial epithelial cells undergo squamous differentiation. In addition, we characterized the genomic structure of this gene and mapped it to human chromosome 12p12 using fluorescence in situ hybridization (FISH).

\section{MATERIALS AND METHODS}

RT-PCR. The first-strand CDNA was reverse transcribed using the first-strand CDNA synthesis kit (Clontech), with $1 \mu \mathrm{g}$ of total RNA isolated from squamous-differentiated (grown without retinoic acid) or mucous secretory (grown in the presence of retinoic acid) human bronchial epithelial cells (obtained for Dr. Karen Guzman, NIEHS) as template. This human CDNA was used in PCR to amplify the homologous region of human $C L-20$. The PCR primers UI ( $5^{\prime}-$ GCATCTGTAGGTCTTTGGAG) and U 7 (5'-TTTCTCAGGACCAGATAGAG) were designed after the coding sequence of rabbit CL-20 (Marvin et al., 1995). The PCR amplification mixture (100 $\mu \mathrm{l}$ ) contained $1 \times$ PCR buffer, $1.5 \mathrm{mM} \mathrm{MgCl}, 200 \mu \mathrm{M}$ each of the four dNTPs, $0.5 \mu \mathrm{M}$ U1 primer, $0.5 \mu \mathrm{M}$ U7 primer, $10 \mu$ l diluted CDNA, and 5 units of AmpliTaq DNA polymerase (Perkin-Elmer/Cetus). The PCR was carried out as 30 cycles of 94,55 , and $72^{\circ} \mathrm{C}$ for $1 \mathrm{~min}$ each and 1 cycle of $72^{\circ} \mathrm{C}$ for $7 \mathrm{~min}$ in a DNA thermal cycler 480 (Perkin-EImer/Cetus). A PCR product of the expected size (370 bp) was isolated from the agarose gel, directly subcloned with the TA cloning kit (Invitrogen), and sequenced. It was then used as a probe to screen a human lung CDNA library.

cDNA library screening. A human lung cDNA library constructed in Lambda ZAP (Stratagene) was obtained from Dr. Shu Wu (NIEHS). The 370-bp RT-PCR product was labeled with $\left[\alpha-{ }^{32} \mathrm{P}\right] \mathrm{dCTP}$ ( $3000 \mathrm{Ci} / \mathrm{mmol}$; Amersham) using the Prime-it RmT Random Primer Labeling kit (Stratagene) and purified using the NucTrap probe purification column (Stratagene). About $5 \times 10^{5}$ plaques were screened. The plaques were lifted onto Hybond- $\mathrm{N}$ membranes (Amersham). DNA was denatured, neutralized, and cross-linked to the membranes using the Stratalinker 2400 (at 120,000 $\mu$ J of UV energy; Stratagene). Hybridization was carried out using the Quikhyb rapid hybridization solution (Stratagene). Twenty-nine positive clones were obtained, of which 4 containing the largest insert were purified. The

${ }^{5}$ The HGMW-approved symbol for the gene described in this paper is EMP1. cloned inserts were excised from the lambda vector in vivo to form the pBluescript SK $(-)$ phagemids using ExAssist helper phage and the SOLR strain (Stratagene). All 4 inserts contained a poly $(A)^{+}$tail and encoded various lengths of hCL-20. The CDNA clone hCL-20-5 containing an insert of $2.8 \mathrm{~kb}$ encoded virtually the whole hCL-20 mRNA and was used in further experiments.

DNA sequencing. Plasmid and phagemid DNA were purified using Wizard miniprep or midiprep kits (Promega). Manual sequencing was performed using the dideoxynucleotide chain-termination method and the Sequenase Quick-denature plasmid sequencing kit (Amersham). Automatic sequencing was carried out using a DyeTerminator Cycle Sequencing Ready Reaction kit (Perkin-EImer) and an ABI Prism 377 automatic sequencer. DNA and deduced protein sequences were analyzed by the UWGCG (Devereux et al., 1984) and MacVector (IBI) sequence analysis software packages.

Isolation of $\mathrm{P} 1$ vector clones. $\mathrm{P} 1$ vector clones containing 75- to $150-\mathrm{kb}$ fragments of genomic DNA encoding the human CL-20 gene were obtained by screening a P1 vector library by PCR using two specific primers (Pierce et al., 1992; Genome Systems, St. Louis, MO). The forward primer 100F starting at nt 100, 5'-GTAGATGCATCAGTAGGTCTT, and the reverse primer $246 \mathrm{R}$ starting at nt 246, 5'GAAGACCAGGAGGGCAATGAC, were designed from the human $\mathrm{CL}-20$ coding sequence described in this paper. The following amplification cycles were employed: 30 cycles of 94,60 , and $72^{\circ} \mathrm{C}$ for $1 \mathrm{~min}$ each and 1 cycle of $72^{\circ} \mathrm{C}$ for $7 \mathrm{~min}$. This yielded one specific PCR product of about 250 bp from human placental genomic DNA (Oncogene Science, Uniondale, NY). One of the P1 vector clones was used for further investigation. DNA from this clone was digested with BamHI and/or HindIII, and fragments were analyzed by Southern analysis using the complete cDNA insert (2.8 kb) from hCL-20-5 as a probe. Fragments hybridizing to the $\mathrm{CL}-20-5$ probe were subcloned into Bluescript SKII and sequenced. The size of the first intron was determined by PCR using a Long PCR kit (Boehringer Mannheim).

Fluorescence in situ hybridization. The regional chromosomal localization was determined by FISH using fragments of genomic DNA containing the human $C L-20$ gene cloned into $P 1$ vectors as a probe (Stokke et al., 1995). The FISH was carried out by Genome Systems. Two different methods were employed. In the first method, DNA was labeled with digoxigenin-dUTP by nick-translation. Labeled probe was combined with sheared DNA and hybridized to normal metaphase chromosomes derived from PHA-stimulated peripheral blood lymphocytes from a male donor. Specific hybridization signals were detected by incubating the hybridized slides with fluoresceinated anti-digoxigenin antibodies followed by counterstaining with 4',6 diamidino-2-phenylindole. In the second method, the labeled P1 vector DNA was cohybridized with a biotin-labeled probe specific for the centromere of chromosome 12. The latter results in the specific labeling of the centromeric region of chromosome 12 after incubation with Texas red-labeled avidin. A total of 80 metaphase cells were analyzed, of which 65 exhibited specific labeling.

Northern blot analysis. Human multiple tissue Northern blots were purchased from Clontech. A blot containing total RNA isolated from human bronchial epithelial cells cultured with and without retinoic acid (100 nM) was obtained from Dr. Karen Guzman (NIEHS). The blots were hybridized using ${ }^{32} \mathrm{P}$-labeled probes for $\mathrm{CL}$ 20, transglutaminase type I (Floyd and J etten, 1989), $\beta$-actin (Clontech), and glyceral dehyde-3-phosphate dehydrogenase (pGAD28; Dugaiczyk et al., 1983) under the same conditions as described above for cDNA library screening.

\section{RESULTS AND DISCUSSION}

Cloning of human CL-20 CDNA. With primers U1 and $U 7$ (Materials and Methods) designed from the coding sequence of the rabbit CL-20 (Marvin et al., 1995), we succeeded in amplifying a specific RT-PCR product of $370 \mathrm{bp}$ from total RNA isolated from human 
AAACACGGTGAAAAGAAACCGCCCATTACACACCCCAGTACACCAGCAGAGGAAACTTAT 60 AACCTCGGGAGGCAGGTCCTTCCCCTCAGTGCGGTCACATACTTCCAGAAGAGCGGACCA 120 GGGCTGCTGCCAGCACCTGCCACTCAGAGCGCCTCTGTCGCTGGGACCCTTCAGAACTCT 180 CTTTGCTCACAAGTTACCAAAAAAAAAAGAGCCAACATGTTGGTATTGCTGGCTGGTATC 240 $\begin{array}{llllllllll}M & \text { L } & \text { V } & \text { I } & \text { I } & \text { A } & \text { G } & \text { I } & 8\end{array}$

TTTGTGGTCCACATCGCTACTGTTATTATGCTATTTGTTAGCACCATTGCCAATGTCTGG 300 $\begin{array}{lllllllllllllllllllll}\mathbf{F} & \mathbf{V} & \mathbf{V} & \mathbf{H} & \mathrm{I} & \mathbf{A} & \mathbf{T} & \mathbf{V} & \mathrm{I} & \mathbf{M} & \mathrm{I} & \mathbf{F} & \mathrm{V} & \mathbf{S} & \mathbf{T} & \mathrm{I} & \mathbf{A} & \mathbf{N} & \mathrm{V} & \mathbf{W} & 28\end{array}$

TTGGTTTCCAATACGgTAGATgCATCAGTAGgTCTTTGGAAAAACTGTACCAACATTAGC 360 $\begin{array}{lllllllllllllllllllll}L & V & S & N & T & V & D & A & S & V & G & I & W & K & N & C & T & N & I & S & 48\end{array}$

TGCAGTGACAGCCTGTCATATGCCAGTGAAGATGCCCTCAAGACAGTGCAGGCCTTCATG 420

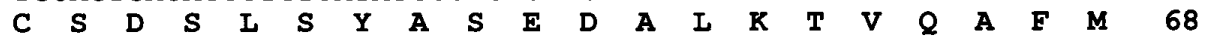

ATTCTCTCTATCATCTTCTGTGTCATTGCCCTCCTGGTCTTCGTGTTCCAGCTCTTCACC 480 $\begin{array}{lllllllllllllllllllll}I & I & S & I & I & F & C & V & I & A & I & I & V & F & V & F & Q & I & F & T & 88\end{array}$

ATGGAGAAGGGAAACCGGTTCTTCCTCTCAGGGGCCACCACACTGGTGTGCTGGCTGTGC 540 $\begin{array}{lllllllllllllllllllll}\mathbf{M} & \mathbf{E} & \mathbf{K} & \mathbf{G} & \mathbf{N} & \mathbf{R} & \mathbf{F} & \mathbf{F} & \mathrm{L} & \mathbf{S} & \mathbf{G} & \mathbf{A} & \mathbf{T} & \mathbf{T} & \mathrm{I} & \mathbf{V} & \mathbf{C} & \mathbf{W} & \mathrm{I} & \mathbf{C} & 108\end{array}$

ATTCTTGTGGGGGTGTCCATCTACACTAGTCATTATGCGAATCGTGATGGAACGCAGTAT 600 $\begin{array}{lllllllllllllllllllll}\text { I } & \text { I } & \text { V } & \text { G } & \text { V } & \text { S } & \text { I } & \text { Y } & \text { T } & \text { S } & \text { H } & \text { Y } & \text { A } & \text { N } & \text { R } & \text { D } & \text { G } & \text { T } & \text { Q } & \text { Y } & 128\end{array}$ CACCACGGCTATTCCTACATCCTGGGCTGGATCTGCTTCTGCTTCAGCTTCATCATCGGC 660

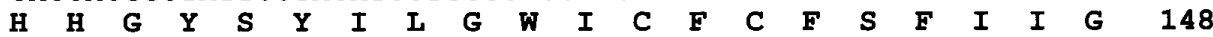
GTTCTCTATCTGGTCCTGAGAAAGAAATAAGGCCGGACGAGTTCATGGGGATCTGGGGGG 720

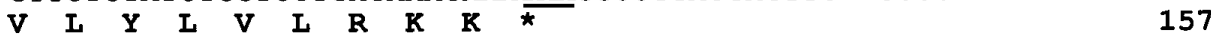

TGGGGAGGAGGAAGCCGTTGAATCTGGGAGGGAAGTGGAGGTTGCTGTACAGGAAAAACC 780 GAGATAGGGGAGGGGGGAGGGGGAAGCAAAGGGGGGAGGTCAAATCCCAAACCATTACTG 840 AGGGGATTCTCTACTGCCAAGCCCCTGCCCTGGGGAGAAAGTAGTTGGCTAGTACTTTGA 900 TGCTCCCTTGATGGGGTCCAGAGAGCCTCCCTGCAGCCACCAGACTTGGCCTCCAGCTGT 960 TCTTAGTGACACACACTGTCTGGGGCCCCATCAGCTGCCACAACACCAGCCCCACTTCTG 1020 GGTCATGCACTGAGGTCCACAGACCTACTGCACTGAGTTAAAATAGCGGTACAAGTTCTG 1080 GCAAGAGCAGATACTGTCTTTGTGCTGAATACGCTAAGCCTGGAAGCCATCCTGCCCTTC 1140 TGACCCAAAGCAAAACATCACATTCCAGTCTGAAGTGCCTACTGGGGGGCTTTGGCCTGT 1200 GAGCCATTGTCCCTCTTTGGAACAGATATTTAGCTCTGTGGAATTCAGTGACAAAATGGG 1260 AGGAGGAAAGAGAGTTTGTAAGGTCATGCTGGTGGGTTAGGTAAACCAAGAAGGAGACCT 1320 TTTCACAATGGAAAACCTGGGGGATGGTCAGAGCCCAGTCGAGACCTCACACACGGCTGT 1380 CCСTCATGGAGACCTCATGCCATGGTCTTTGCTAGGCCTCTTGCTGAAAGCCAAGGCAGC 1440 TCTTCTGGAGTTTCTCTAAAGTCACTAGTGAACAATTCGGTGGTAAAAGTACCACACAAA 1500 CTATGGGATCCAAGGGGCAGTCTTGCAACAGTGCCATGTTAGGGTTATGTTTTTAGGATT 1560 CCCCTCAATGCAGTCAGTGTTTCTTTTAAGTATACAACAGGAGAGAGATGGACATGGCTC 1620 ATTGTAGCACAATCCTATTACTCTTCCTCTAACATTTTTGAGGAAGTTTTGTCTAATTAT 1680 CAATATTGAGGATCAGGGCTCCTAGGCTCAGTGGTAGCTCTGGCTTAGACACCACCTGGA 1740 GTGATCACCTCTTGGGGACCCTGCCTATCCCACTTCACAGGTGAGGCATGGCAATTCTGG 1800 AAGCTGATTAAAACACACATAAACCAAAACCAAACAACAGGCCCTTGGGTGAAAGGTGCT 1860 ATATAATTGTGAAGTATTAAGCCTACCGTATTTCAGCCATGATAAGAACAGAGTGCCTGC 1920 ATTCCCAGGAAAATACGAAAATCCCATGAGATAAATAAAAATATAGGTGATGGGCAGATC 1980 TTTTCTTTAAAATAAAAAAGCAAAAACTCTTGTGGTACCTAGTCAGATGGTAGACGAGCT 2040 GTCTGCTGCCGCAGGAGCACCTCTATACAGGACTTAGAAGTAGTATGTTATTCCTGGTTA 2100 AGCAGGCATTGCTTTGCCCTGGAGCAGCTATTTTAAGCCATCTCAGATTCTGTCTAAAGG 2160 GGTTTTTTGGGAAGACGTTTTCTTTATCGCCCTGAGAAGATCTACCCCAGGGAGAATCTG 2220 AGACATCTTGCCTACTTTTCTTTATTAGCTTTCTCCTCATCCATTTCTTTTATACCTTTC 2280 CTTTTTGGGGAGTTGTTATGCCATGATTTTTGGTATTTATGTAAAAGGATTATTACTAAT 2340 TCTATTTCTCTATGTTTATTCTAGTTAAGGAAATGTTGAGGGCAAGCCACCAAATTACCT 2400 AGGCTGAGGTTAGAGAGATTGGCCAGCAAAAACTGTGGGAAGATGAACTTTGTCATTATG 2460 ATTTCATTATCACATGATTATAGAAGGCTGTCTTAGTGCAAAAAACATACTTACATTTCA 2520 GACATATCCAAAGGGAATACTCACATTTTGTTAAGAAGTTGAACTATGACTGGAGTAAAC 2580 CATGTATTCCCTTATCTTTTACTTTTTTTCTGTGACATTTATGTCTCATGTAATTTGCAT 2640 TACTCTGGTGGATTGTTCTAGTACTGTATTGGGCTTCTTCGTTAATAGATTATTTCATAT 2700 ACTATAATTGTAAATATTTTGATACAAATGTTTATAACTCTAGGGATATAAAAACAGATT 2760 CTGATTCCCA

FIG. 1. Nucleotide and deduced amino acid sequence of human CL-20. The amino acid sequence is noted bel ow the nucleotide sequence. The translation start site (nucleotide 217), the stop codon (nucleotide 688), and the polyadenylation signal (nucleotide 2747) are shown in boldface and are underlined. Three AUUUA instability motifs in the 3'-UTR are also indicated in boldface. Nucleotides and amino acids are numbered on the right side of the sequence. 
A

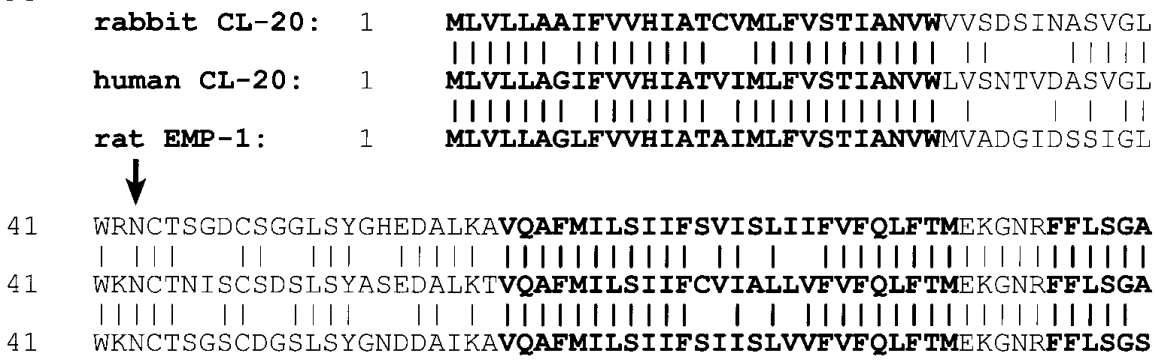

101 TMLVCWLCVLIGASIYTHRYANGD SNTFDRSHHGYSF ILAWICFCFSFVVGVLYLVLRKK | |||l|| | | ||| || | |||||||| |||||||| |||||||||| TTLVCWLCILVGVSIYTSHYANRDGTQY . . . HHGYSYILGWICFCF SF I IGVLYLVLRKK

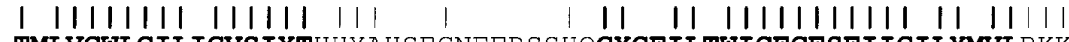

101 TMLVCWLCILIGVSIYTHHYAHSEGNF FP SSHQGYCF ILTWICF CF SF I IGILYMVLRKK

B

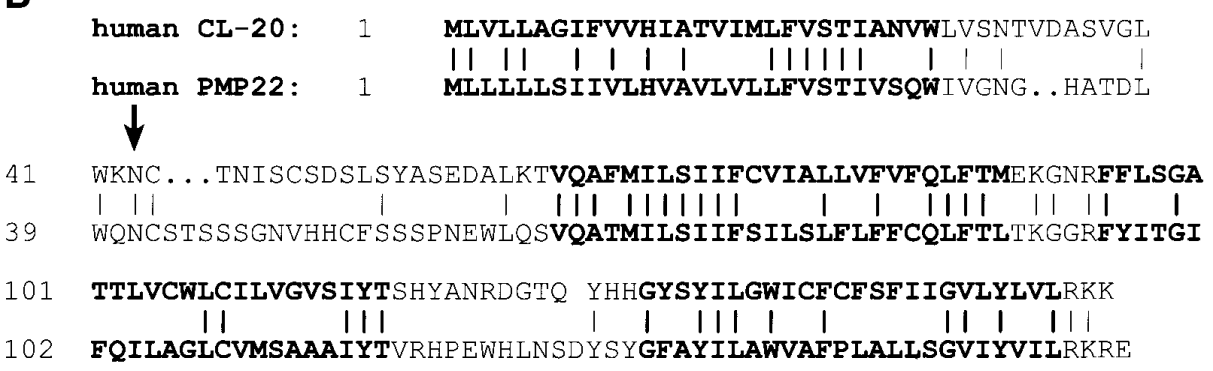

FIG. 2. Comparison between the amino acid sequence of hCL-20 and several family members. Vertical lines indicate identical amino acids. The conserved, potential $\mathrm{N}$-glycosylation site is indicated by an arrow, and the four conserved hydrophobic domains are indicated by boldface letters. (A) Alignment of the amino acid sequences of human CL-20, rabbit CL-20, and rat EMP-1. (B) Alignment of the amino acid sequences of human CL-20 and human PMP22.

bronchial epithelial cells. Sequence analysis showed that this PCR fragment was highly similar to rabbit CL-20 and likely part of the human homologue of this gene.

To obtain the full-length CDNA of human CL-20, we screened a human lung CDNA library using this fragment as a probe. From $5 \times 10^{5}$ plaques screened, 29 putative positive clones were obtained in the initial screening, of which 4 were purified. The cloned inserts were excised and cloned into the pBluescript SK(-) phagemid for sequencing analysis. The sequences of the 4 cDNA clones were analyzed and found to be identical. All four clones contained a poly $(A)^{+}$tail, $3^{\prime}$-untranslated region ( $3^{\prime}-U T R$ ) and full coding region but varied in the length of their $5^{\prime}-U T R$. The CDNA clone hCL-20-5, containing the longest insert of $2.8 \mathrm{~kb}$, encoded virtually the whole hCL-20 mRNA. A putative translation start site was found 217 nucleotides from the 5 '-end of the cDNA. The open reading frame terminated with a stop codon 472 nucleotides downstream from the initiation codon, indicating that it encodes a protein of 157 amino acids (Fig. 1). hCL-20 contains a large 3 '-untranslated region of about $2 \mathrm{~kb}$ that contains three AUUUA instability motifs and a putative TATAAA polyadenylation signal.

Protein sequence comparison of CL-20 with PMP 22 and EMP-1. As shown in Fig. 2A, the deduced human
CL-20 amino acid sequence exhibits a $76 \%$ identity with the rabbit CL-20 protein (Marvin et al., 1995) and the rat E MP-1 protein (Taylor et al ., 1995), which might constitute the rat homologue of CL-20. The amino acid sequence identity between rabbit CL-20 and rat EMP1 is also 76\%. Computer analysis identified two potential $\mathrm{N}$-glycosylation sites at amino acids $\mathrm{N}_{43}$ and $\mathrm{N}_{46}$ of human CL-20, the first one being conserved in rabbit CL-20 and rat EMP-1. In addition, four hydrophobic regions spanning amino acids $1-28,64-89,95-117$, and 131-154, which can also be found in rabbit CL-20 and rat EMP-1, were identified in human CL-20 (bold amino acids in Fig. 2A). In particular the four hydrophobic domains are highly conserved, while the hydrophilic regions show a high degree of diversity.

As shown in Fig. 2B, human CL-20 exhibits a 39\% identity with the human PMP22 protein, with the conserved amino acids predominantly located within the four hydrophobic domains. The highest identity (91\%) is found in an 11-amino-acid region (VQATMILSIIF) within the second hydrophobic domain. The high homology of this region between these proteins supports the concept that these amino acids constitute a functionally important domain. Recently, a structural model of PMP22 has been proposed in which the four hydrophobic domains span the membrane either as a $\beta$-sheet or as an $\alpha$-helix (Patel and Lupski, 1994). 


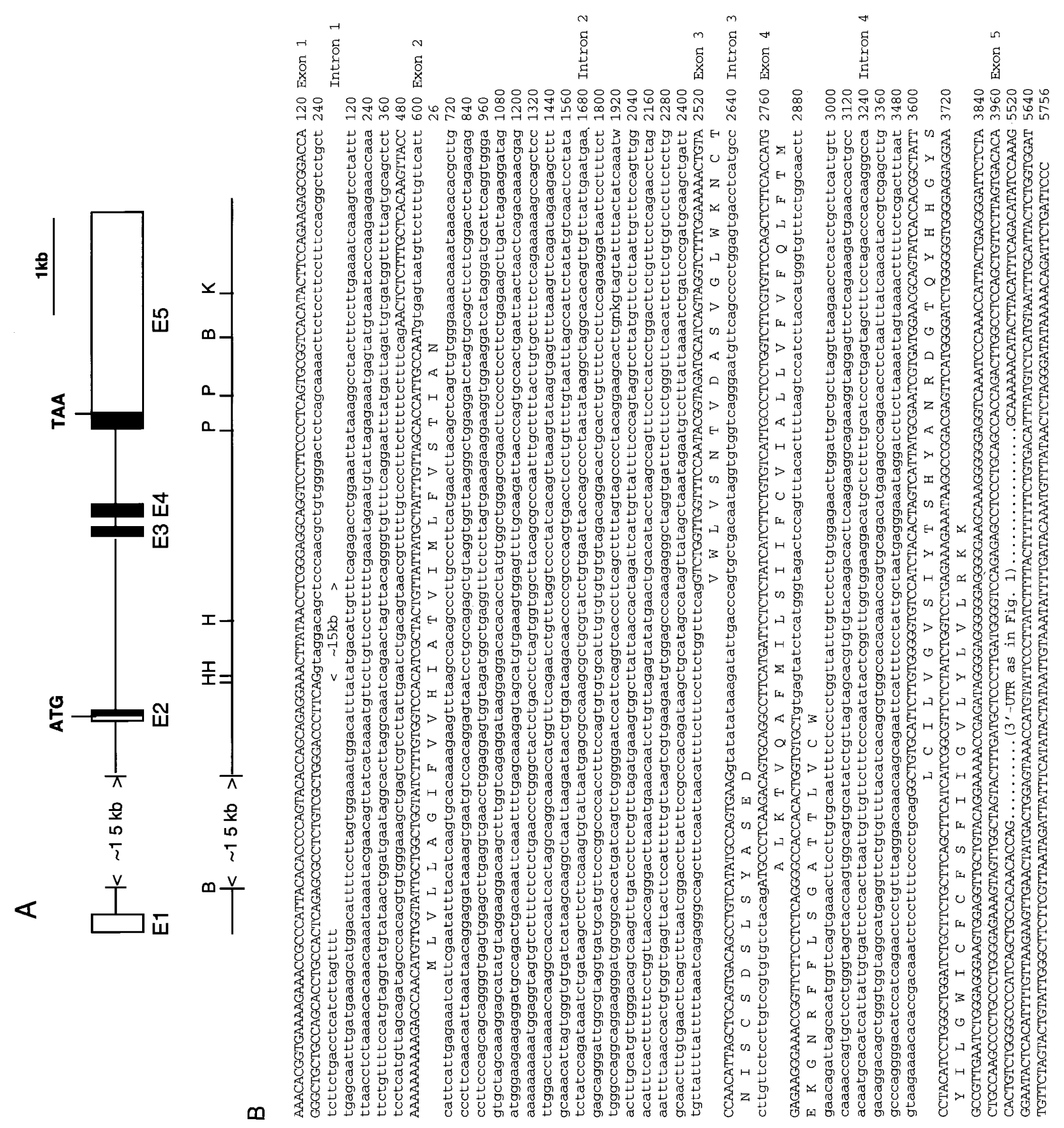


Based on its structural similarity with PMP22, CL-20 probably also functions as a membrane protein. Both rabbit CL-20 and human PMP22 are able to bind the monoclonal antibody NHK-1, which recognizes epitopes composed of sulfated carbohydrates, indicating that CL-20 and PMP22 are glycosylated (Hammer et al., 1993; Snipes et al ., 1993; J etten, unpublished observations). This glycosylation most likely occurs at the highly conserved, potential glycosylation site $\mathrm{N}_{43}$. Although the function of this epitope in $C L-20$ and PMP22 has yet to be identified, the HNK-1 epitope has been shown to play a role in cell-cell recognition processes in other proteins (Schachner and Martini, 1995).

Most mutations in PMP22 associated with hereditary motor and sensory neuropathies are located within the membrane-spanning domains (Patel and Lupski, 1994). Several mutations have been identified within the highly conserved 11-amino-acid region (VQAF MILSIIF) in the second hydrophobic domain and involve amino acids that are identical between PMP22 and CL20. This provides additional support for the functional importance of this region. In addition, one may speculate that putative mutations in the same region of $\mathrm{CL}$ 20 could be involved as well in certain disease processes.

Structure of the hCL-20 gene. P1 vector dones containing 75- to $100-\mathrm{kb}$ fragments of genomic DNA that include the CL-20 gene were isolated by screening a P1 vector library by PCR using two specific primers, $100 \mathrm{~F}$ and $246 \mathrm{R}$, that under appropriate conditions yielded a PCR product of about $250 \mathrm{bp}$ with human genomic DNA as template. P1 vector DNA was cut with $\mathrm{BamHI}$ and subjected to Southern analysis using ${ }^{32} \mathrm{P}$ hCL-20-5 as a probe. The fragments hybridizing to the complete cDNA fragment of hCL-20-5 were subcloned into Bluescript and sequenced. The hCL-20 gene contained five exons and four introns (Fig. 3). The nucleotide sequence of the exons was identical to that obtained for the hCL-20-5 cDNA. The first intron in the hCL-20 gene was approximately $15 \mathrm{~kb}$ and located within the $5^{\prime}$-UTR between $\mathrm{G}_{174}$ and $A_{175}$ of the hCL-205 cDNA. The other introns were located in the coding region. The second intron of about $1.9 \mathrm{~kb}$ was located between $T_{294}$ and $G_{295}$, the third intron of 102 bp between nucleotides $G_{391}$ and $A_{392}$, and the fourth intron of $710 \mathrm{bp}$ between nucleotides $T_{532}$ and $G_{533}$. A summary of the exon/intron junctions is presented in Table 1. The sequences of these junctions are consistent with the consensus $\left(A_{62} G_{77} / g_{100} t_{100} a_{60} a_{74} g_{88}\right.$ for the $5^{\prime}$ donor and $\mathrm{y}_{87} n \mathrm{y}_{97} \mathrm{a}_{100} \mathrm{~g}_{100} / \mathrm{G}_{55}$ for the $3^{\prime}$ acceptor side) for
TABLE 1

\section{DNA Sequences of the Exon/Intron J unctions of Human CL-20}

5 ' exon/intron junction Intron size (kb)

3'-exon/intron junction

$\begin{array}{lcl}\text { CTTCAG }_{174} \text { gtagga } & \sim 15 & \text { ttcagA }_{175} \text { ACTCT } \\ \text { GCCAAT }_{294} \text { gtgagt } & 1.889 & \text { ttcagG }_{295} \text { TCTGG } \\ \text { GTGAAG }_{391} \text { gtatat } & 0.102 & \text { ctacagA }_{392} \text { TGCCC } \\ \text { TGTGCT }_{532} \text { gtgagt } & 0.71 & \text { tgcagG }_{533} \text { GCTGT }\end{array}$

Note. Exon sequences are shown in uppercase letters and intron sequences in lowercase letters. The nucleotide numbers indicate the 5'- and $3^{\prime}$-positions in the human CL-20-5 cDNA (Fig. 1) that flank each intron.

known splice sites within eukaryotic genes (Mount, 1982). It is interesting to note that the exon/intron junctions interrupt the coding sequence of human CL-20 at the same locations as reported for PMP22 (Suter et al., 1994), corroborating that these two genes belong to the same family and are likely derived from duplications of a common ancestral gene.

Chromosomal localization of human CL-20. The regional chromosomal localization was determined by FISH using fragments of genomic DNA containing the human $C L-20$ gene cloned into $P 1$ vectors as a probe (Stokke et al., 1995). DNA of a positive P1 clone was labeled with digoxigenin and hybridized to metaphase chromosomes derived from PHA-stimulated peripheral blood lymphocytes from a male donor. Results of this analysis indicated that CL-20 is localized on human chromosome 12 . This was confirmed by the colocalization of a bi otin-labeled probe specific for the centromere of chromosome 12 . The regional assignment of the $\mathrm{CL}$ 20 probe was determined by the analysis of the fractional chromosome length; 10 specifically hybridized chromosomes were measured. These calculations indicated that the CL-20 gene mapped to a position that is $56 \%$ of the distance from the centromere to the teIomere of chromosome arm 12p, an area that corresponds to 12p12. The result of the in situ hybridization is shown in Fig. 4A. An idiogram indicating the chromosomal localization of human CL-20 is presented in Fig. 4B. The mapping of hCL-20 to chromosome 12 by FISH is in agreement with our previous findings using a panel of hybrid human/hamster cell lines (Marvin et al., 1995). The localization of hCL-20 is distinct from that of hPMP22, which has recently been mapped to chromosome 17p11.2- p12 (Martinotti et al., 1992; Matsunami et al., 1992; Roa et al., 1993). Mutations and duplications in the latter gene have been found in asso-

FIG. 3. Genomic structure of the human $C L-20$ gene. (A) Schematic presentation of the genomic structure of the human $C L-20$ gene. The start codon (ATG) and stop codon (TAA) are indicated. Boxes indicate exons; black boxes indicate coding region. B, H, S, and K represent BamHI, HindIII, Pstl, and Kpnl, respectively, (B) Sequenced region of the human CL-20 gene. Uppercase letters indicate exon sequences and lowercase letters intron sequences. The coding regions are marked by single-letter amino acid code. The sequence of the complete $3^{\prime}-$ UTR was obtained from genomic DNA and found to be identical to that obtained from genomic DNA and found to be identical to that obtained from the cDNA clone hCL-20-5 shown in Fig. 1. The sequence has been submitted to GenBank under Accession No. U77085. 

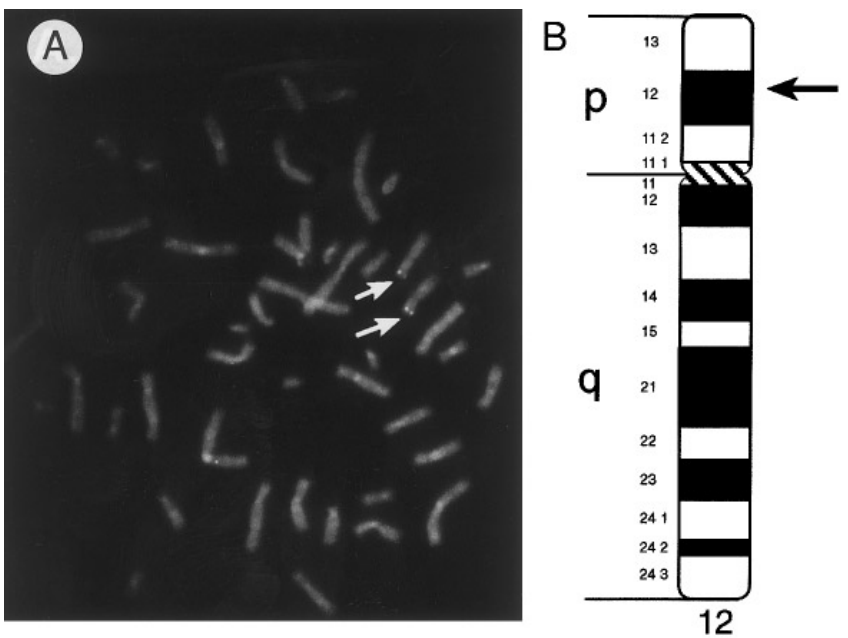

FIG. 4. Regional mapping of the $h C L-20$ gene by fluorescence in situ hybridization to human chromosome 12p12. (A) The location of the hCL-20 gene was identified using a digoxigenin-dUTP-labeled genomic fragment containing the $\mathrm{hCL}-20$ gene. Colocalization on chromosome 12 was determined by cohybridization with a biotinylated probe specific for the centromere of chromosome 12. Only the staining for hCL-20 is shown. (B) The idiogram indicates that hCL20 maps to band 12p12. The arrow indicates the interval within which the hybridization signal was detected on a sample of 80 chromosomes. No specific signal was detected on other chromosomes.

ciation with several neuropathies (Valentijn et al., 1992; Matsunami et al., 1992; Roa et al., 1993; Patel and Lupski, 1994; Chance et al., 1994; Nicholson et al., 1994). Various genetic alterations involving the $12 \mathrm{p} 12$ locus have been identified in breast fibrosarcomas (Calabrese et al., 1991), lymphoblastic leukemia (Cave et al., 1995), and cardiac myxoma (Dijkhuizen et al., 1995). Future studies must determine what role the CL-20 gene plays in disease.

Tissuedistributions of human CL-20 mRNA. To examine the pattern of CL-20 expression in different human tissues, we analyzed the levels of CL-20 mRNA by Northern blot analysis. As shown in Fig. 5, the 2.8$\mathrm{kb}$ CL-20 transcript can be detected in many of the tissues examined, including heart, placenta, lung, skeletal muscle, kidney, spleen, thymus, prostate, testis, ovary, small intestine, and col on; but not in brain, liver, pancreas, or peripheral blood leukocytes. A $\beta$-actin probe was used to compare the relative level of RNA loaded. Several differences in the expression pattern between CL-20 and E M P-1 are noticeable. In particular the expression of CL-20 in the colon appears less than that reported for EMP-1 (Taylor et al., 1995). Future studies must elucidate whether CL-20 and EMP-1 are homologues of the same gene or represent two different members of this gene family.

The expression of CL-20 is differentially regulated by retinoids. Previous studies have shown that the induction of rabbit CL-20 mRNA expression is closely correlated with squamous differentiation and that retinoids, which inhibit squamous differentiation, also re- press the induction of rabbit CL-20 (Marvin et al., 1995). To examine the regulatory effect of retinoids on CL-20 expression in human cells, we analyzed the mRNA level in human bronchial epithelial (HBE) cells cultured in the presence or absence of retinoic acid by Northern blot analysis. In the absence of retinoic acid, HBE cells undergo squamous differentiation and, as shown in Fig. 6, CL-20 was highly expressed, as indicated by the strong band representing the $2.8-\mathrm{kb} \mathrm{CL}$ 20 mRNA (lane 2). However, squamous differentiation is inhibited in the presence of retinoic acid and instead, HBE cells undergo differentiation into mucous cells (Gray et al., 1996). Under this condition the expression of CL-20 was greatly suppressed, as indicated by the dramatic decrease in the hybridization signal of the 2.8-kb CL-20 transcript (Fig. 6, lane 2). The levels of CL-20 mRNA correlate with those of transglutaminase type I mRNA (Floyd and J etten, 1989), which is not expressed in retinoic acid-treated HBE cells but is

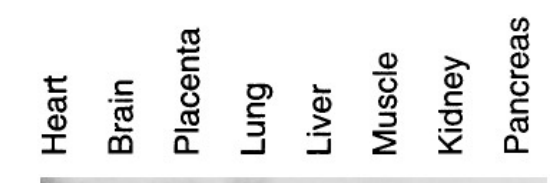

CL-20

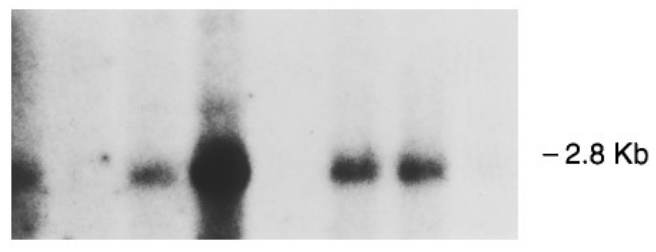

$\beta$-Actin
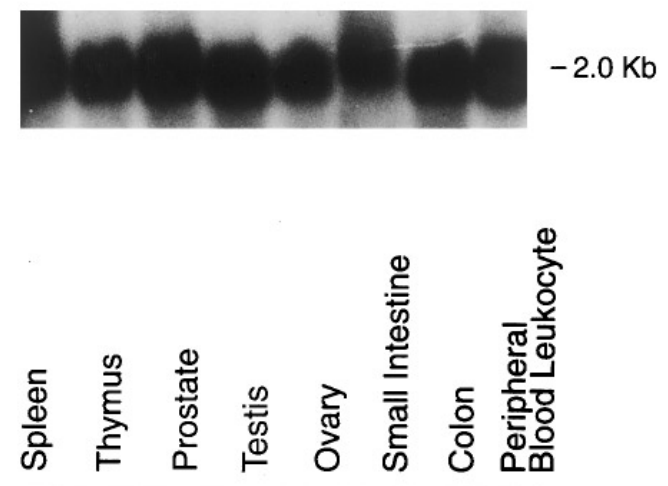

CL-20

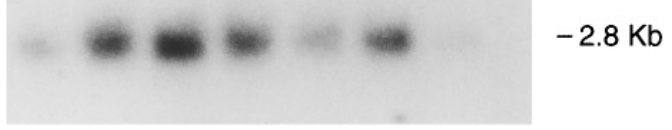

$\beta$-Actin

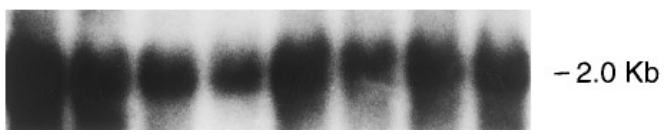

FIG. 5. Tissue-specific expression of human CL-20 mRNA. Poly $(A)^{+}$RNA from different human tissues was examined by Northern blot analysis with ${ }^{32} \mathrm{P}$-labeled $\mathrm{CL}-20$ and $\beta$-actin probes as described under Materials and Methods. The 2.8-kb CL-20 and 2.0-kb $\beta$-actin transcript are indicated on the right. 


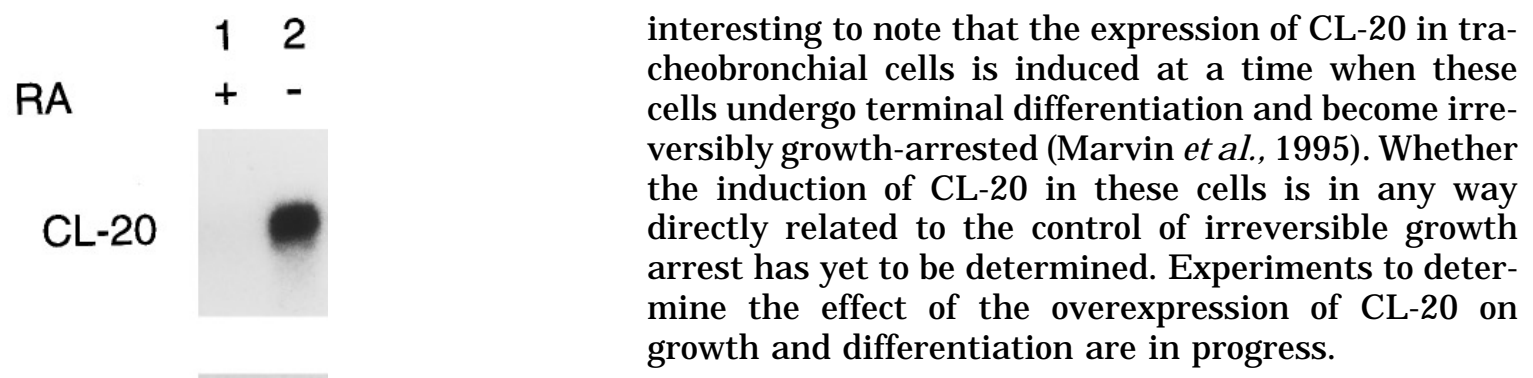

TGase I

GPDH

\section{ACKNO WLEDGMENTS}

The authors thank Dr. L. Zhang for comments on the manuscript, K. Guzman for providing the RNA from HBE cells, S. Wu for the lung cDNA library, and S. Austin for technical assistance.

Note added in proof. During review of this paper Ruegg, C. L., et al. (J . Immunol. 157: 72-80, 1996) reported the cDNA sequence of a novel gene $B 4 B$ which is identical to the human homologue of EMP1/CL-20.

\section{REFERENCES}

FIG. 6. Differential expression of human $C L-20$ in squamous-
differentiated and mucous-secretory $\mathrm{HBE}$ cells. Total RNA from retinoic acid-treated (100 nM) and untreated HBE cells was examined by Northern blot analysis as described under Materials and Methods using ${ }^{32} \mathrm{P}$-labeled probes for hCL-20, transglutaminase Type I (TGase I), and glyceraldehyde-3-phosphate dehydrogenase (GPDH). The 2.8kb CL-20 mRNA, 2.8-kb transglutaminase type I, and the 1.3-kb GPDH mRNA are indicated.

highly expressed in squamous cells (Fig. 6). Taking into account differences in exposure time and the fact that total RNA was used instead of poly $(A)^{+}$RNA, the expression of $C L-20$ was estimated to be at least 50 times higher in squamous-differentiating HBE cells than in any of the tissues used in Fig. 5. These results are in agreement with previous observations showing an association between high expression of CL-20 and squamous differentiation (Marvin et al., 1995).

The functional roles of CL-20 and PMP22 have not been precisely established. PMP 22 has been shown to be expressed in neural as well as nonneural tissues during embryonic development and in the adult (Manfioletti et al., 1990; Welcher et al., 1991; Baechner et al., 1995). These observations support the concept that PMP22 serves, in addition to its important structural role in maintaining myelin compaction in peripheral nerves, other functions including the regulation of cellular differentiation and proliferation. The dual role of PMP22 is supported by findings demonstrating that the regulation of this gene is controlled by two promoters (Suter et al., 1994). Recently, it was shown that overexpression of PMP22 induces apoptosis in NIH 3T3 fibroblasts (Fabbretti et al., 1995). In addition, PMP22 is induced when 3T3 fibroblasts undergo growth arrest (Ciccarelli et al., 1990), and in Schwann cells it delays the transition from the G1- to the S-phase in the cell cycle (Zoidl et al., 1995). These observations suggest a role for PMP22 in the control of cell growth. It is

Baechner, D., Liehr, T., Hameister, H., Altenberger, H., Grehl, H., Suter, U., and Rautenstrauss, B. (1995). Widespread expression of the peripheral myelin protein-22 gene (pmp22) in neural and non-neural tissues during murine development. J . Neurosci. Res. 42: $733-741$.

Calabrese, G., Di Virgilio, C., Cianchetti, E., Franchi, P. G., Stuppia, L., Parruti, G., Bianchi, P. G., and Palka, G. (1991). Chromosome abnormalities in breast fibroadenomas. Genes Chromosomes Cancer 3: 202-204.

Cave, H., Gerard, B., Martin, E., Guidal, C., Devaux, I., Weissenbach, J ., Elion, J ., Vilmer, E., and Grandchamp, B. (1995). Loss of heterozygosity in the chromosomal region 12 p12- 13 is very common in childhood acute lymphoblastic leukemia and permits the precise Iocalization of a tumor suppressor gene distinct from p27KIP1. Blood 86: 3869-3875.

Ciccarelli, C., Philipson, L., and Sorrentino, V. (1990). Regulation of expression of growth arrest-specific genes in mouse fibroblasts. Mol. Cell. Biol. 10: 15295- 15297.

Chance, P. F., Abbas, N., Lensch, M. W., Pentao, L., Roa, B. B., Patel, P. I., and Lupski, J . R. (1994). Two autosomal dominant neuropathies result from reciprocal DNA duplication/deletion of a region on chromosome 17. Hum. Mol. Genet. 3: 223- 228.

Devereux, J ., Haeberli, P., and Smithies, O. (1984). A comprehensive set of sequence analysis programs for the VAX. Nucleic Acids Res. 12: 387- 395 .

Dijkhuizen, T., van den Berg, E., Molenaar, W. M., Meuzelaar, J . J ., and de J ong, B. (1995). Rearrangements involving 12p12 in two cases of cardiac myxoma. Cancer Genet. Cytogenet. 82: 161- 162.

Dugaiczyk, A. D., Haron, J . A., Stone, E. M., Dennison, O. E., Rothblum, K. N., and Schwartz, R. J . (1983). Cloning and sequencing of a ribonucleic acid copy of glyceraldehyde-3-phosphate dehydrogenase messenger isolated from chicken muscle. Biochemistry 22: 1605- 1613.

Eckert, R. L., and Rorke, E. A. (1989). Molecular biology of keratinocyte differentiation. Environ. Health Perspect. 80: 109- 116.

Fabbretti, E., Edomi, P., Brancolini, C., and Schneider, C. (1995). Apoptotic phenotype induced by overexpression of wild-type gas3/ PMP22: Its relation to the demyelinating peripheral neuropathy CMT1A. Genes Dev. 9: 1846- 1856.

Floyd, E. E., and J etten, A. M. (1989). Regulation of type I (epider- 
mal) transglutaminase mRNA levels during squamous differentiation: Down-regulation by retinoids. Mol. Cell. Biol. 9: 4846-4851.

Gray, T.E., Guzman, K., Davis, C. W., Abdullah, L. H., and Nettesheim, P. (1996). Mucociliary differentiation of serially passaged normal human tracheobronchial epithelial cells. Am. J . Respir. Cell. Mol. Biol. 14: 104-112.

Hammer, J . A., O'Shannessy, D. J ., De Leon, M., Gould, R., Zand, D., Daune, G., and Quarles, R. H. (1993). Immunoreactivity of PMP-22, P0, and other 19-28 kD glycoproteins in peripheral nerve myelin of mammals and fish with HNK-1 and related antibodies. J. Neurochem. 35: 546- 558.

J etten, A. M., Nervi, C., and Vollberg, A. M. (1992). Control of squamous differentiation in tracheobronchial and epidermal epithelial cells: Role of retinoids. J . Natl. Cancer Inst. 13: 93- 100.

Manfioletti, G., Ruaro, M. E., Del Sal, G., Philipson, L., and Schneider, C. (1990). A growth-arrest-specific (gas) gene codes for a membrane protein. Mol. Cell. Biol. 10: 2924- 2930.

Martinotti, A., Cariani, C.T., Melani, C., Sozzi, G., Spurr, N. K., Pierotti, M. A., and Colombo, M. (1992). I solation and mapping to $17 p 12-13$ of the human homologous of the murine growth arrest specific Gas-3 gene. Hum. Mol. Genet. 1: 331- 334.

Marvin, K. W., George, M. D., Fugimoto, W., Saunders, N. A., Bernacki, S. H., and J etten, A. M. (1992). Cornifin, a crosslinked envelope precursor in keratinocytes that is down-regulated by retinoids. Proc. Natl. Acad. Sci. USA 89: 11026-11030.

Marvin, K. W., Fujimoto, W., and J etten, A. M. (1995). I dentification and characterization of a novel squamous cell-associated gene related to PMP22. J . Biol. Chem. 270: 28910-28916.

Matsunami, N., Smith, B., Ballard, L., Lensch, M. W., Robertson, M., Albertsen, H., Hanemann, C. O., Muller, H. W., Bird, T. D., White, R., and Chance, P. F. (1992). Peripheral myelin protein-22 gene maps in the duplication in chromosome $17 \mathrm{p} 11.2$ associated with Charcot-Marie-Tooth 1A. Nature Genet. 1: 176-179.

Mount, S. M. (1982). A catalogue of splicejunction sequences. Nucleic Acids Res. 10: 459-472.

Nicholson, G. A., Valentijn, L. J ., Cherryson, A. K., Kennerson, M. L., Bragg, T. L., DeKroon, R. M., Ross, D. A., Pollard, J . D., McLeod, J.G., Bolhuis, P.A., and Bass, F. (1994). A frame shift in the PMP22 gene in hereditary neuropathy with liability to pressure palsies. Nature Genet. 7: 263-266.

Patel, P. I., Roa, B. B., Welcher, A. A., Schoener-Scott, R., Trask, B. J ., Pentao, L., Snipes, G. J ., Garcia, C. A., Francke, U., Shooter, E. M., Lupski, J . R., and Suter, U. (1992). The gene for the peripheral myelin protein PMP-22 is a candidate for Charcot-MarieTooth disease 1A. Nature Genet. 1: 159- 165.

Pierce, J . C., Sternberg, N., and Sauer, B. (1992). A mouse genomic library in the bacteriophage $\mathrm{P} 1$ cloning system: Organization and characterization. Mamm. Genome 3: 550-559.

Roa, B. B., Dyck, P. J ., Marks, H. G., Chance, P. F., and Lupski, J . R. (1993). Dejerine- Sottas syndrome associated with point mutation in the peripheral myelin protein 22 (PMP22) gene. Nature Genet. 5: $269-273$.

Saunders, N. A., and J etten, A. M. (1994). Control of growth regula- tory and differentiation-specific genes in human keratinocytes by interferon $\gamma$. J . Biol. Chem. 269: 2016- 2022.

Schachner, M., and Martini, R. (1995). Glycans and the modulation of neural recognition molecule function. Trends Neurosci. 18: 183191.

Sereda, M., Griffiths, I., Puhlhofer, A., Stewart, H., Rossner, M. J ., Zimmerman, F., Magyar, J . P., Schneider, A., Hund, E., Meinck, H. M., Suter, U., and Nave, K. A. (1996). A transgenic rat model of Charcot-Marie-Tooth disease. Neuron 16: 1049- 1060.

Snipes, G. J ., Suter, U., Welcher, A. A., and Shooter, E. M. (1992). Characterization of a novel peripheral nervous system myelin protein (PMP-22/SR 13). J . Cell Biol. 117: 225-238.

Snipes, G. J ., Suter, U., Welcher, A. A., and Shooter, E. M. (1993). Human peripheral myelin protein-22 carries the L 2/HNK-1 carbohydrate epitope. J . Neurochem. 61: 1961- 1964.

Stokke, T., Collins, C., Kuo, W. L., Kowbel, D., Shadravan, F., Tanner, M., Kallioniemi, A., Kallioniemi, O. P., Pinkel, D., Deaven, L., et al. (1995). A physical map of chromosome 20 established using fluorescence in situ hybridization and digital analysis. Genomics 26: $134-137$.

Suter, U., Welcher, A. A., Ozcelik, T., Snipes, G. J ., Kosaras, Francke, U., Billings-Gagliardi, S., Sidman, R. L., and Shooter, E. M. (1992). Trembler mouse carries a point mutation in a myelin gene. Nature 356: $241-244$.

Suter, U., Snipes, G. J ., Schoener-Scott, R., Welcher, A. A., Pareek, S., Lupski, J.R., Murphy, R. A., Shooter, E. M., and Patel, P. I. (1994). Regulation of tissue-specific expression of alternative peripheral myelin protein-22 (PMP22) gene transcripts by two promoters. J . Biol. Chem. 269: 25795-25808.

Taylor, V., Welcher, A.A., Amgen EST Program, and Suter, U. (1995). Epithelial membrane protein-1, peripheral myelin protein 22, and lens membrane protein 20 define a novel gene family. J . Biol. Chem. 270: 28824-28833.

Timmerman, V., Nelis, E., Van Hul, W., Nieuwenhuijsen, B. W., Chen, K. L., Wang, S., Othman, K. B., Cullen, B., Leach, R. J ., Hanemann, C. O., De J onghe, P., Raeymaekers, P., van Ommen, G. B., Martin, J -J ., Müller, H. W., Vance, J . M., Fischbeck, K. H., and Van Broeckhoven, C. (1992). The peripheral myelin protein gene PMP-22 is contained within the Charcot-Marie-Tooth disease type 1A duplication. Nature Genet. 1: 171- 175.

Valentijn, L. J ., Bolhuis, P. A., Zorn, I., Hoogendijk, J . E., van den Bosch, N., Hensels, G. W., Stanton, V. P., Housman, D. E., Fischbeck, K. H., Ross, D. A., Nicholson, G. A., Meershoek, E. J ., Dauwerse, H. G., van Ommen, G. B., and Baas, F. (1992). The peripheral myelin gene PMP22/gas3 is duplicated in Charcot-Marie-Tooth disease type 1A. Nature Genet. 1: 166-170.

Welcher, A. W., Suter, U., De Leon, M., Snipes, G.J ., and Shooter, E. M. (1991). A myelin protein is encoded by the homologue of a growth arrest-specific gene. Proc. Natl. Acad. Sci. USA 88: 71957199.

Zoidl, G., Blass-Kampmann, S., D'Urso, D., Schmalenbach, C., and Muller, H. W. (1995). Retroviral-mediated gene transfer of the peripheral myelin protein PMP22 in Schwann cells: Modulation of cell growth. EMBO J . 14: 1122-1128. 